\title{
Prospective Primary School Teachers' Attitudes towards Probability and its Teaching
}

\author{
Assumpta Estrada ${ }^{1}$, Carmen Batanero ${ }^{2 *}$ \\ ${ }^{1}$ University of Lleida, SPAIN \\ 2 University of Granada, SPAIN

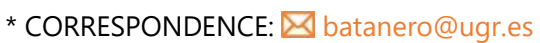

\begin{abstract}
Since probability is a new topic at the primary school level in many countries, many primary school teachers may consider themselves not well prepared or may not value the formative role of probability as a topic for their students to learn. Consequently, the assessment of teachers' attitudes using valid and reliable instruments is a preliminary step in organizing formative actions for these teachers. In Estrada, Batanero and Díaz (2018), we described the development of a scale aimed at measuring primary school teachers' attitudes towards probability and the teaching of probability. In this new paper we complete the above research and present the results of applying the questionnaire to a sample of 416 prospective primary school teachers. We analyze the results related to the different items, subscales, and total score in the scale, and explore the influence of some variables on the participants' attitudes.
\end{abstract}

Keywords: attitudes, probability, teaching probability, prospective teachers

\section{INTRODUCTION}

Probability is an important topic in the mathematics curriculum at all levels in many countries (Australian Curriculum, Assessment and Reporting Authority [ACARA] 2010; Common Core State Standards Initiative [CCSSI] 2010 or New Zealand Ministry of Education [ME] 2007), due to the need of probabilistic literacy for all the citizens (Gal, 2005). In Spain (MECD, 2014), the topic is considered in the curriculum guidelines from the first grade (6-year-old students) on, including content from the Standards developed by the National Council of Teachers of Mathematics (NCTM, 2000).

The introduction of this topic in the education of all citizens reflects the need to overcome deterministic thinking and to accept the existence of fundamental chance in nature (Batanero et al., 2016). At the same time, we need to equip citizens with strategies and ways of reasoning that can help them in making adequate decisions in everyday and professional situations in which chance is present. We also observe a change in the teaching approach towards the frequentist view, which is grounded in simulation and experiments with the aim of providing children with a stochastic experience from their childhood.

However, the impact of curricular proposals directly depends on teachers' willingness to and interest in teaching the given topic. In the case of probability many prospective and in-service primary school teachers may feel uncomfortable when teaching in case the teaching they received was based on definitions of new concepts or examples of procedures for solving mathematics problems. Because of a routine learning these teachers may not value probability or consider themselves not well prepared to teach the topic (Groth \& Meletiou-Mavrotheris, 2018).

Article History: Received 2 September $2019 \bullet$ Revised 24 September $2019 \bullet$ Accepted 24 September 2019

(C) 2020 by the authors; licensee Modestum Ltd., UK. Open Access terms of the Creative Commons Attribution 4.0 International License (http://creativecommons.org/licenses/by/4.0/) apply. The license permits unrestricted use, distribution, and reproduction in any medium, on the condition that users give exact credit to the original author(s) and the source, provide a link to the Creative Commons license, and indicate if they made any changes. 
In this paper we focus on attitudes towards probability and its teaching. Given that improving the attitudes of teachers is a goal of statistics education (Tishkovskaya \& Lancaster, 2012), the assessment of attitudes is particularly relevant in the preparation of teachers. The reason is that teachers with a positive attitude towards a topic are more likely to transmit this attitude to their students (Gal \& Ginsburg, 1994). To fulfil this need, we started a research project that was oriented to inform about the prospective teachers attitudes towards probability and towards the teaching of probability. In a first step we developed a valid and reliable questionnaire that is useful for this purpose and is described in detail in Estrada, Batanero and Díaz (2018). In this new paper we complete the above research and present the results of applying the questionnaire to a sample of 416 prospective primary school teachers. We analyze the results related to the different items, subscales, and total score in the scale, and explore the influence of some variables on the participants' attitudes. In the next sections we present the theoretical framework and method, and present the results of the study.

\section{THEORETICAL FRAMEWORK}

\section{Attitudes and their Relevance in Education}

Attitudes have received increasing attention in the past years, given the influence of the affective domain on the learning of mathematics and its influence on cognitive processes such as creativity, intuition or visualization (Attard et al., 2016). Moreover, according to the OECD (2013), students' attitudes, beliefs and emotions play a significant role in their interest and response to mathematics in general, and their employment of mathematics in their individual lives.

Attitudes take part of the affective domain in mathematics education (Gómez-Chacón, 2000; Phillipp, 2007), which include emotions, attitudes, and beliefs. These constructs differ in the stability of the affective responses that they represent, the degree to which cognition plays a role and the time they take to develop. Attitudes change more slowly than emotions and more quickly than beliefs. Gil, Blanco, and Guerrero (2006) suggest that attitudes is the most researched topic within the emotional domain of mathematics because unfortunately pupils generate negative attitudes towards mathematics along their studies, and some of them present an authentic aversion to the discipline, hence the interest to investigate the composition and development of attitudes.

One of the first authors conceptualizing attitudes in mathematics education is and McLeod (1992, p. 581) who defined attitudes as "Affective responses that involve negative or positive feelings of moderate intensity." Philipp (2007) described attitudes as ways of acting, feeling, or thinking that show a person's disposition or opinion towards a topic and Kislenko (2009) as an affective response including negative or positive feelings of moderate stability and strength.

For Ajzen (1989, p. 241) attitudes are viewed as "Individual's disposition to respond favourably or unfavourably to an object, person, institution, or event, or to any other discriminable aspect of the individual's world," while Gal et al. (1997, p. 40) consider attitudes as "A summation of emotions and feelings experienced over time in the context of learning mathematics or statistics."

According to Di Martino and Zan (2015), attitudes act as a bridge between beliefs and emotions, and include both beliefs (about oneself and about mathematics) and emotions. Attitudes towards a topic emerge from experiences with learning the topic in school or outside of school and students may also transfer their attitudes about mathematics in general towards probability (Estrada et al. 2011). For example, Martínez-Sierra, and García González. (2014) observed the development of positive or negative attitudes during problem solving depending on the students' ability to get the solution of the problem. Attitudes are relatively stable, their cognitive component is stronger than emotions, develop as a result of repeated positive or negative emotional responses, and are fixed over time.

Attitudes might influence a person's behaviour in relation to the topic inside and outside the classroom, as well as their willingness to learn more of the topic (Gal et al. 1997). Moreover, according to Veloo and Chairhany (2013), a student's attitude is the main factor in his or her orientation to learning a topic. It is therefore important for teacher educators to identify prospective teachers' attitudes towards the topics they are to teach, and to use this knowledge in taking appropriate measures to improve these attitudes (Veloo \& Chairhany 2013).

Although there is a wide research related to attitudes towards statistics (Carmona, 2004; Nolan, Beran, \& Hecker, 2012), the number of studies focusing on teachers is much smaller. Moreover, these studies have 
concentrated on attitudes towards statistics and not on attitudes towards the teaching of statistics and none of them focus on probability.

There is general consensus in the mathematics education community that teachers need to develop adequate probabilistic knowledge and reasoning. However, many teachers, in particular primary school teachers, have only studied theoretical probability and lack experience in designing investigations or simulations in the classroom context (Kvatinsky \& Even, 2002; Stohl, 2005). Moreover, recent research suggests that many prospective teachers hold the same biases about probabilistic reasoning as their students (Batanero et al., 2014; Liu \& Thompson, 2007).

Teachers should also be acquainted with research results that describe children's reasoning and beliefs in uncertain situations and with didactic materials and technological resources that can help their students develop correct intuitions in this area. Finally, it is important to consider teachers' beliefs and attitudes, since according to Veloo and Chairhany (2013), positive attitudes about learning mathematics and probability have a positive effect on developing understanding. In fact, positive attitudes are also a major contributor in the learning of probability ((Leavy, Hannigan, \& Fitzmaurice, 2013; Tan et al., 2011).

\section{PREVIOUS RESEARCH}

The few papers with attitudes towards probability involve small samples of students and do not consider teachers or attitudes towards teaching. One of them is the research by Tan et al. (2011), who analysed possible changes in attitudes of 65 students in Malaysia as a consequence of teaching based on graphing calculators. The authors reported significant changes in self-concept in probability, and value of probability. Another study is that by Veloo and Chairhany (2013) in Indonesia with 64 students, where again the attitudes towards probability of students improved after teaching based on technology. In these two studies the scale for assessing attitudes was not specific of probability and did not measure attitudes towards the teaching of probability.

There is a number of scales measuring attitudes towards statistics, such as the Statistics Attitude Survey (SAS; Roberts \& Bilderback, 1980), the Attitudes Toward Statistics survey (ATS; Wise 1985), and the Survey of Attitudes Toward Statistics (SATS; Schau et al., 1995) (see Carmona, 2004 for an analysis of the different scales and their psychometric properties). These scales have been used in a number of different studies both with university students and with teachers.

Research focusing on teachers' attitudes towards statistics suggests varied results (Estrada, Batanero, \& Lancaster, 2011). For example, Onwuegbuzie (1998) compared prospective teachers' and university students attitudes towards statistics using the ATS scale and found poorer results in the teachers. He also concluded that attitudes towards statistics are strongly correlated to learning achievement.

Nasser (2004) analysed the relationships between attitudes towards statistics, statistics anxiety, mathematical and statistical achievement in statistics using the SATS scale of 162 prospective teachers in Egypt and found a small positive effect of attitudes towards statistics on achievement in statistics.

Chick and Pierce (2008) gave 10 items taken from the SATS to 27 prospective primary school teachers and reported that the teachers had neutral attitudes towards statistics. With regards to attitudes about the value of statistics, even when teachers agreed with the item "To be an intelligent consumer, it is necessary to know something about statistics," a majority also agreed that "When buying a new car, asking a few friends is preferable to consulting an owner satisfaction survey in a consumer magazine."

Estrada et al. (2005) administered the SATS instrument to a sample of 367 prospective primary school teachers in Spain. Results showed moderately positive attitudes on cognitive competence and value items. Moreover, liking or disliking statistics was related to the teachers' perception of their capacity to learn statistics and to the value they attributed to statistics. A qualitative analysis of the ten SATS open items that had yielded lower scores (Estrada \& Batanero, 2008) was used to classify the main reasons for positive and negative scorings. This research suggests that two main influences on teachers' attitudes are understanding of statistics and positive learning experiences.

Lancaster (2008) analyzed the attitudes of 56 teachers, including their attitudes towards future professional development in statistics; their knowledge of statistics and their competence to teach statistics and suggested these three components may be related and can vary as a consequence of the study of statistics. 
Estrada et al. (2010) compared the attitudes towards statistics of Spanish and Peruvian primary education teachers and found positive attitudes in both countries with a slight positive difference among Spanish teachers, who found statistics easier than their Peruvians colleagues who suggested that statistics is a more adequate topic of study for science students. In Portugal, Martins et al. (2011, 2012) assessed attitudes towards statistics of in-service primary education teachers. There, teachers were reported to generally like learning and teaching statistics, and considered statistics to be a tool in facing real-world problems and connecting the cognitive and social components of education. There were, however, significant differences in the overall scores according to the teaching cycle, time of service, area of initial training, and statistics study level.

Considered together, these results indicate the need to strengthen teachers' attitudes towards statistics, since these attitudes have a significant effect on teachers' statistical education, their teaching of statistics, and the attitudes of their students. Moreover, our literature review revealed a lack of research related to teachers' attitudes towards probability and its teaching. In Estrada, Batanero and Diaz (2018) we started a research project oriented to fulfil this need and we develop a scale which is described with detail in Estrada et al. (2018). In this new paper we use the same scale.

\section{METHODOLOGY}

\section{Sample}

A total of 416 prospective teachers (aged between 20-25 years) took part in the sample (302 women and 114 men). All the participants had studied some probability previously: 142 of them studied probability for the last time in high school (12-14 years of age), 218 in middle school (17-18 years of age), and 53 of them in other types of studies, such as vocational training. They belonged to different groups in the same university in Catalonia and were in their 3rd year of university, preparing to become primary school teachers. These participants completed a scale that was built by the authors and that is described below.

\section{The APT Attitude Scale}

While various instruments to measure attitudes towards statistics are available, we only found one scale that measures attitude towards learning probability: the Probability Attitude Inventory (PAI), developed for use with undergraduate students (Tan et al., 2011). Moreover, this instrument is not specific of probability, as it was directly built from a scale of attitudes towards mathematics, with only changing the word "mathematics" by "probability" in all the items. Consequently, there was no available instrument aimed at measuring teachers' attitudes towards probability, and even the few instruments for measuring attitudes towards statistics developed specifically for use with teachers do not consider their attitudes towards teaching statistics.

Since attitude is a psychological trait, it is not directly observable and therefore should be inferred from subjects' responses to items on a scale (McDonald, 2013). We developed our own scale aimed at measuring teachers' attitudes towards probability and the teaching of probability, in several steps.

\section{Scale Components, Semantic Definition and Item Selection}

The first step was fixing the semantic definition of the construct attitudes, which we assumed not to be one-dimensional, but to rather be made up of different components that should be specified in advance. By taking into account previous research on attitudes, we decided to use a multidimensional model, which is very common in the study of attitudes. Following Wyer and Albarracín (2014) we identified three components of attitudes: affect, behavior, and cognition. These three components, defined below, are also common in research on attitudes towards statistics (Estrada et al., 2011; Gal \& Ginsburg, 1994; Gómez-Chacón, 2000; Ramirez et al., 2012; Schau et al., 1995).

- Affective component towards probability (AP): It describes the personal feelings about probability (for example, interest or disinterest in the topic, anxiety, fear or pleasure associated to the study of probability.

- Cognitive competence towards probability (CCP): It is the person's perception of his or her competence, knowledge, and intellectual skills to study or apply probability. In the case of teachers, if they have a positive perception of their own abilities with probability they would be more willing to teach the topic. 
- Behavioural component towards probability (BP): Tendency to act in a particular way, for example, tendency to make decisions in random situations or to help other people to learn and use probability.

Since this scale is aimed at teachers, we complemented the three classical attitude components with three additional components of attitude that are related specifically to teaching probability:

- Affective component towards teaching probability (AT): It describes the feelings about teaching probability, which may differ from (although may be associated with) feelings towards probability itself: fear-confidence, interest-disinterest in teaching probability.

- Cognitive component for teaching probability (CT): It is the teacher's perception of his/her ability to teach probability, to help students, to pose effective tasks to seek relevant resources, etc.

- Behavioural component towards teaching probability (BT): Tendency to didactic action: whether the teacher has or has not taught (or whether he/she is willing or not willing to teach) probability, whether he/she gives priority to probability over other topics, and whether he/she thinks the topic should be postponed or given emphasis.

- Finally, we included a Value component towards probability and its teaching (VPT): appreciation of the usefulness, relevance, and importance of probability and its teaching in personal and professional life. Although value has been included as a component of attitude, for example, in Schau et al. (1995), none of the scales analyzed above assess the value attributed to teaching a particular topic.

The second step in building the questionnaire was looking for suitable items that covered the intended components. To achieve this goal, a preliminary pool of items was created by translating and adapting items from different research on attitudes towards statistics, since we expect some relationship between attitudes towards statistics and probability. We examined the following scales, all of them with good psychometric properties:

- Statistics Attitude Survey (SAS) (Roberts \& Bilderback, 1980). This was the first instrument developed to measure attitudes towards statistics. This scale was designed to be one-dimensional, with 33 Likerttype items.

- Attitudes Towards Statistics (ATS) (Wise, 1985). The ATS is a 29-item, Likert-type scale with five response possibilities consisting of two subscales. The Course (9 items) and Field (20 items) subscales respectively aim to measure attitudes towards the particular statistics course in which students are enrolled and the use of statistics in their fields of study.

- Multidimensional Auzmendi's Scale (Auzmendi, 1992). This scale considers attitudes towards both mathematics and statistics. It includes five factors (usefulness, anxiety, confidence, pleasantness, and motivation).

- Survey of Attitudes Towards Statistics (SATS) (Schau et al., 1995). This scale consists of 28 items measuring four components: Affect (feelings about statistics), Cognitive competence (perception of selfcompetence, knowledge, and intellectual skills when applied to statistics), Value (appreciation of the usefulness and value of statistics in personal and professional life), and Difficulty (the perceived difficulty of statistics as a subject). We also analysed a later version (Schau, 2003) that also includes effort and interest as components.

- Scale of Attitudes Towards Statistics (EAEE) (Estrada, 2002). This scale was developed specifically for use with teachers, and considers didactic aspects of attitudes. Its 25 items are distributed across three classical components (affective, cognitive, and behavioural dimensions), in addition to three additional components (social, educational, and instrumental dimensions).

\section{Expert Judgement and Content Validity}

After listing all the items in the different scales, we identified and adapted a pool of 56 items (eight items per component) to the case of probability and its teaching and their format and wording was revised. All of the items were in the format of statements, in response to which respondents scored their level of agreement or disagreement on a five-point Likert scale (from 1: strongly disagree to 5: strongly agree). We decided to use negative and positive sentences to avoid the problem of acquiescence and to take into account different aspects of the pedagogical and didactical components as described before. For example, the sentence "I use probability 
Table 1. Components and corresponding items

\begin{tabular}{ll}
\hline Component & Scale Items \\
\hline Affective component towards probability (AP) & $1,5,16,27$ \\
\hline Cognitive competence towards probability (CCP) & $6,8,17,22$ \\
\hline Behavioural component towards probability (BP) & $2,7,15,18$ \\
\hline Affective component towards teaching probability (AT) & $9,21,26,28$ \\
\hline Teaching probability competence component (CT) & $3,10,14,23$, \\
\hline Behavioural component towards teaching probability (BT) & $11,20,24,25$ \\
\hline Value component towards probability and its teaching (VPT) & $4,12,13,19$ \\
\hline
\end{tabular}

information when making decisions" is related to the behavioural component towards probability, and strong agreement suggests a positive attitude in this component. At the same time, the sentence "probability is only useful for games of chance" is related to the value component, and strong agreement suggests a negative attitude in this component. Scores for items that were presented in negative form were reversed before the scale and component scores wre computed by adding the scores for different items.

The 56 items in the preliminary questionnaire were submitted to 14 expert researchers (statisticians, mathematicians, psychologists, and statistics educators), all of whom were university lecturers with a doctoral degree and with a large experience in teaching probability or in training teachers (or both). Each of these experts provided a numerical value (ranging from 1 to 5) for each item, rating its adequacy for assessing the intended component; the judges also provided suggestions for improving item wording. After performing a statistical analysis of the scores provided by the experts, we selected the four items with the highest average scores and lowest standard deviation for each component so as to assure high adequacy and agreement of experts. All of the items that were selected had an average score of 4 points or greater. This process assured the content validity of the instrument.

The final scale includes 28 items (Appendix), 14 of which are expressed affirmatively (1, 2, 4, 5, 6, 8, 9, $10,14,15,19,20,24$, and 28$)$ and 14 of which are expressed in a negative manner $(3,7,11,12,13,16,17,18$, $21,22,23,25,26$, and 27). The distribution of items according to the components is presented in Table 1 , where we see that the same number of items and about the same number of negative and positive wordings of items were included in each component.

\section{Pilot Trials and Reliability}

The instrument was administered to two different pilot samples of prospective primary school teachers in Spain with ages ranging between 20 and 24 years. The instrument reliability was quite high (Cronbach's Alpha $=.934$, for the first sample of $n=71$ prospective teachers, and Cronbach's Alpha=.892, for the second sample $(\mathrm{n}=232)$. In this second sample we also computed the reliability for the different components $(\mathrm{AP}=.759$, $\mathrm{CCP}=.637, \mathrm{BP}=.537, \mathrm{AT}=.713, \mathrm{CT}=.612, \mathrm{BT}=.584, \mathrm{~V}=.599)$, still acceptable, according to Nunnally (1978), in the first steps of exploratory research. These values of reliability are similar to those reported for the components of some studies of attitudes towards statistics, as reviewed in Carmona (2004).

In order to check the items discriminative power, we ordered the subjects by their total score on the questionnaire and compared the scores for each item for the upper the $70 \%$ percentile in the total score and the lower $30 \%$ percentile in the total score. We obtained statistically significant differences in the t-test of difference of averages in independent groups except for one item ( $p$-value $<.001$ ), which suggests a high discriminative power of the questionnaire items.

An exploratory factor analysis with principal components as the extraction method yielded seven factors with eigenvalues higher than 1 and thus confirmed the suggested structure of the questionnaire and its construct validity. These seven factors accounted for the $67.99 \%$ of the explained variance in the model.

\section{RESULTS \\ Global Results}

The questionnaire was administered at the beginning of the second semester of the academic year 20182019. Results for each item are included in the Appendix with an average value per item ranged from 2.76 to 4.42 , with a mean of 3.7 and a standard deviation of .42 (while the expected average value was 3 ). The mean total score for the scale was $\bar{x}=101.5$, with a standard deviation of $\sigma=13.9$. Since the theoretical "neutral" 


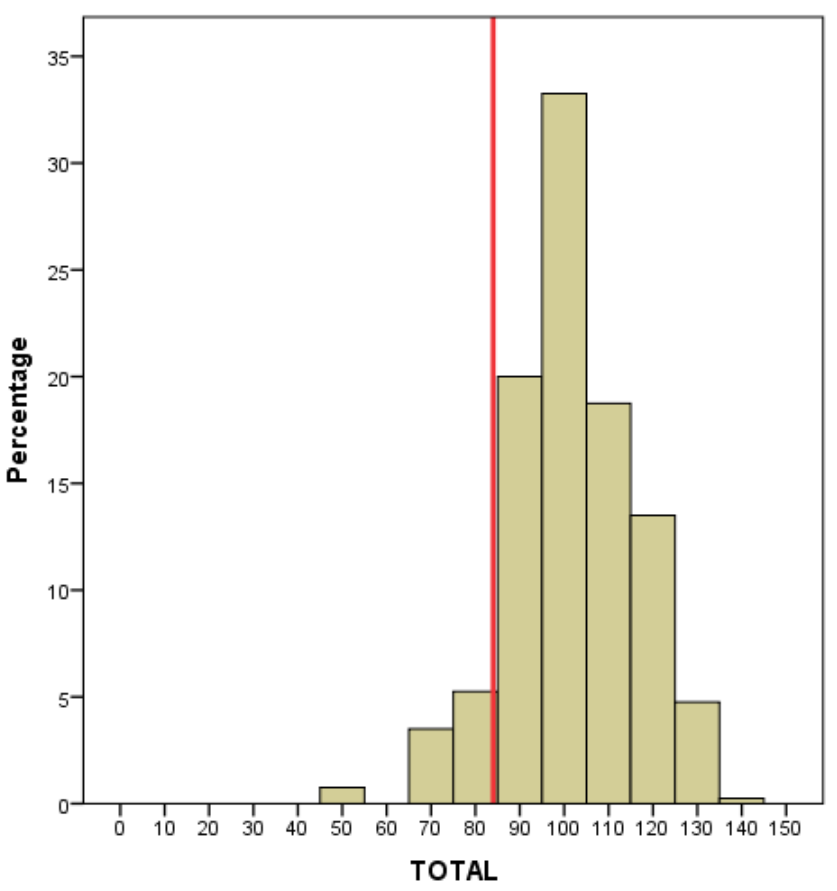

Figure 1. Distribution of the total score in the scale

score (when a participant answers with a score of 3 to all the items) is 84 , the results suggest a slightly positive attitude towards probability and its teaching in this sample of students. Since the scores in items with negative wording were reversed a high score in these items still implies a positive attitude.

The items with the highest scores (4 or more points on average, and very similar scores in the pilot sample) were I25 (If I could skip a topic, I would skip probability; $\bar{x}=4.42$ ), I12 (Probability is only useful for games of chance; $\bar{x}=4.37$, I17 (Probability is understandable only to "science people"; $\bar{x}=4.27$ ); I26 (I am not interested in teaching probability, even if it appears in the curriculum; $\overline{\mathrm{x}}=4.18$ ); I13 (Probability is not as valuable as other areas of mathematics; $\overline{\mathrm{x}}=4.13$ ), and I11 (I will only teach probability if there is time available after teaching the other topics; $\bar{x}=4.1$ ). Since these items are written in a negative form, the scores were tranformed before computing the averages and therefore the meaning of these high scores is that participants consider probability as a valuable and easy theme and they are willing to teach it. The items with the lowest scores (scores below 3 points) were item I8 (I have mastered the main contents of probability; $\overline{\mathrm{x}}=2.75$ ), I14 (It will be easy for me to design assessment tasks related to probability $\overline{\mathrm{x}}=2.76$ ), and I6 (probability is easy; $\overline{\mathrm{x}}=$ 2.9). Thus, according to these results, the prospective teachers in the study perceive the difficulty of the topic, and do not feel well prepared enough in either the mathematical or the pedagogical content to do so.

In Figure 1, we display the distribution of the total score for the entire questionnaire in the whole sample and observe that the majority of students are distributed above the theoretical mean value of 84 , marked by a red line on the graph, which suggests that these prospective teachers have a generally positive attitude towards probability; this finding coincides with the results of the two pilot samples (Estrada et al., 2018).

Statistics summaries for the total score and the scores in the different components of attitudes are presented in Table 2. Since each component is made of 4 items, the theoretical mean in each of them is 12 . The means of the different components are higher than the theoretical mean (12) and the standard deviations are quite small as compared with the mean. These results points to positive and homogeneous results in the attitudes of these teachers across the seven components.

The components with the highest scores correspond to value attributed to probability and its teaching (VPT) and the participants' willingness to teach probability (BT), while the lowest (but still positive) scores correspond to cognitive competence towards probability (CCP), and affect to probability (AP). Our interpretation is that these teachers recognize the value of probability and its teaching and are willing to teach probability, but feel not well prepare for this task and do not like particularly the topic. 
Table 2. Mean and standard deviation of the items, total score, and components in the second sample

\begin{tabular}{cccccc}
\hline Variable & Mean & St. deviation & Variable & Mean & St. deviation \\
\hline Scale & 101,50 & 13.93 & AT & 14.11 & 2.72 \\
\hline AP & 13.42 & 2.89 & CT & 14.65 & 2.44 \\
\hline CCP & 13,32 & .13 & BT & 15.68 & 2.38 \\
\hline BP & 14.28 & 2.65 & VPT & 15.89 & 2.28 \\
\hline
\end{tabular}

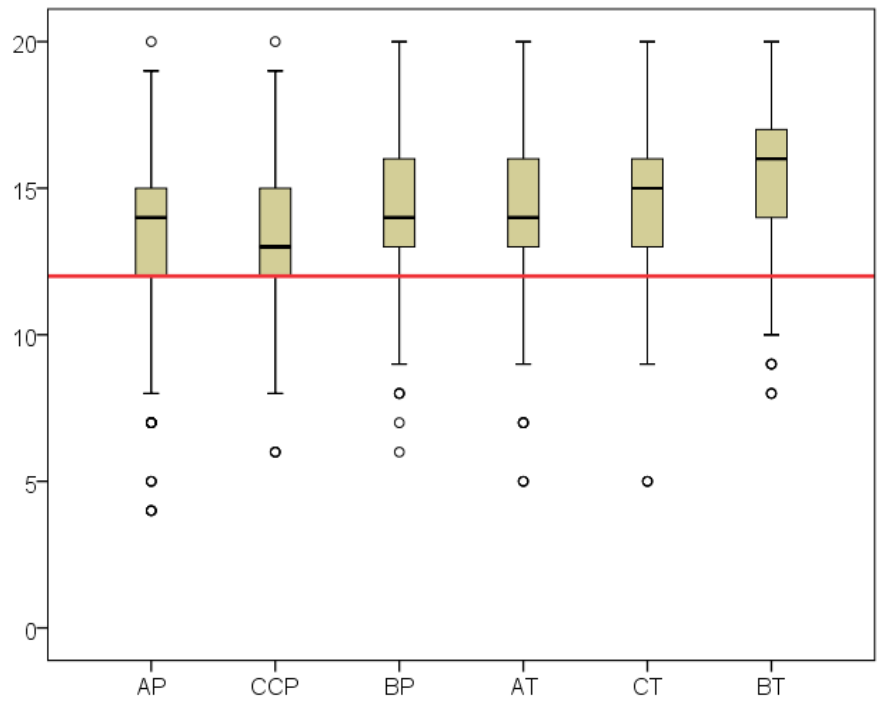

Figure 2. Distribution of the scores in the different components of attitude

Table 3. Pearson's correlation between components of attitudes

\begin{tabular}{ccccccccc}
\hline & Total Score & AP & CCP & BP & AT & CT & BT & VPT \\
\hline Total Score & 1 & $.612^{* *}$ & $.437^{* *}$ & $.741^{* *}$ & $.661^{* *}$ & $.565^{* *}$ & $.299^{* *}$ & $.810^{* *}$ \\
\hline AP & $.612^{* *}$ & 1 & $.398^{* *}$ & $.702^{* *}$ & $.635^{* *}$ & $.437^{* *}$ & $.339^{* *}$ & $.770^{* *}$ \\
\hline CCP & $.437^{* *}$ & $.398^{* *}$ & 1 & $.382^{* *}$ & $.479^{* *}$ & $.467^{* *}$ & $.473^{* *}$ & $.677^{* *}$ \\
\hline BP & $.741^{* *}$ & $.702^{* *}$ & $.382^{* *}$ & 1 & $.766^{* *}$ & $.636^{* *}$ & $.315^{* *}$ & $.846^{* *}$ \\
\hline AT & $.661^{* *}$ & $.635^{* *}$ & $.479^{* *}$ & $.766^{* *}$ & 1 & $.776^{* *}$ & $.435^{* *}$ & $.872^{* *}$ \\
\hline CT & $.565^{* *}$ & $.437^{* *}$ & $.467^{* *}$ & $.636^{* *}$ & $.776^{* *}$ & 1 & $.571^{* *}$ & $.820^{* *}$ \\
\hline BT & $.299^{* *}$ & $.339^{* *}$ & $.473^{* *}$ & $.315^{* *}$ & $.435^{* *}$ & $.571^{* *}$ & 1 \\
\hline VPT & $.810^{* *}$ & $.770^{* *}$ & $.677^{* *}$ & $.846^{* *}$ & $.872^{* *}$ & $.820^{* *}$ & $.611^{* *}$ & 1 \\
\hline
\end{tabular}

** Significant $(\mathrm{p}<0.01)$

The whole distribution of the scores in the different components are displayed on Figure 2, where we marked with an horizontal red line the theoretical neutral point (average theoretical score). Not only the medians of these distributions are located over the theoretical mean, but in all the components the lower quartile is situated on or over this neutral point. Again, our results suggest in general very good attitudes of these teachers towards probability and its teaching.

The Pearson correlation coefficient between scores in the scale and the different components and between the different components are given in Table 3, which shows that the component which most influence the global attitude (Total score) are value of probability and its teaching (VPT), behavior towards probability (BP), attitudes towards teaching (AT) and affect towards probability (AP), while the less influential component is behavior towards the teaching of probability (BT).

Moreover, the components correlate significantly and in particular all of them are correlated with value of probability and its teaching (VPT). As regards the main correlation with affect towards teaching (AT) are affect toward probability (AP), behavior towards probability (BP) and cognitive competence for teaching (CT).Our interpretation is that affect towards probability and use of probability influences affect towards teaching and perceived competence to teach the topic, with less influence of other factors such as cognitive competence or value attributed to probability. 
Table 4. Results of t- test of differences (women -men) and 95\% confidence intervals

\begin{tabular}{cccccc}
\hline & & & & \multicolumn{2}{c}{$\mathbf{9 5 \%}$ confidence interval } \\
\hline & $\mathbf{t}$ & $\mathbf{p}-$ value & Difference (women-men) & Lower value & Upper value \\
\hline Total Score & -1.304 & .193 & -2.02625 & -5.08168 & 1.02918 \\
\hline AP & -2.51 & $.041^{*}$ & -.64970 & -1.27225 & -.02715 \\
\hline CCP & -2.026 & $.043^{*}$ & -.58508 & -1.15286 & -.01730 \\
\hline BP & -2.820 & $.005^{* *}$ & -.80891 & -1.37275 & -.24508 \\
\hline AT & -1.710 & .088 & -.50725 & -1.09023 & .07573 \\
\hline CT & -1.632 & .103 & -.43542 & -.95974 & .08890 \\
\hline BT & 1.925 & .055 & .49922 & -.01052 & 1.00895 \\
\hline VPT & .642 & .193 & .16016 & -.33003 & .65036 \\
\hline *Significant $(\mathrm{p}<0.05) ; * *$ Highly significant $(\mathrm{p}<.01)$ & & &
\end{tabular}

Table 5. Results of Anova according to different factors

\begin{tabular}{cccccccccc}
\hline & \multicolumn{4}{c}{ Last time of study } & \multicolumn{3}{c}{ Specialty } & \multicolumn{3}{c}{ Access } \\
\hline & F & d.f. & p-value & F & d.f. & p-value & F & d.f. & p-value \\
\hline Total Score & 2.829 & 2 & .06 & 2.797 & 4 & $.026^{*}$ & 1.931 & 3 & .125 \\
\hline AP & 2.985 & 2 & .052 & 4.050 & 4 & $.003^{* *}$ & 2.04 & 3 & .10 \\
\hline CCP & 4.772 & 2 & $.009^{* *}$ & 3.255 & 4 & $.01^{* *}$ & .24 & 3 & .869 \\
\hline BP & 1.967 & 2 & .141 & 2,216 & 4 & .067 & 2.114 & 3 & .098 \\
\hline AT & 1,875 & 2 & .155 &, 638 & 4 & .635 & 1.49 & 3 & .217 \\
\hline CT & 2.027 & 2 & -.133 & 2,350 & 4 & .054 & 3.684 & 3 & .012 \\
\hline BT & 4.322 & 2 & $.014^{*}$ & 1.316 & 4 & .263 & 1.741 & 3 & .158 \\
\hline VPT & 2.829 & 2 & .060 & 3.904 & 4 & $.004^{* *}$ & 1.602 & 3 & .188 \\
\hline
\end{tabular}

*Significant $(\mathrm{p}<0.05) ; * *$ Highly significant $(\mathrm{p}<.01)$

\section{Variables Affecting Attitudes}

A second part of our analysis is the study of the possible influence of some variables on the participants' attitudes. First of all, we explored the possible differences by gender, because, there is a long history of research that suggest the influence of gender in affective variables (Attard et al., 2016). Moreover, in spite that there is under-representation of females in the more challenging mathematics subjects studied at university in different careers, in the case of education women are over represented because the particular interest of women in children and in educating the children.

For each component and for the total score we computed the t- test of differences of means in independent samples and the $95 \%$ confidence interval of the difference of women and men. Results are presented in Table 4. We found significant differences in affect towards probability (AP) and cognitive competence towards probability (CP) and a highly significant difference in behavioural component towards probability (BP). In all these components the score of girls were lower than that of boys, and then confirmed the worst attitudes of women in the sample as compare with their men colleagues.

We additionally performed a study of the differences in the total score and each components for each of the following factors, using anova: a) Last time of study of statistics (primary or secondary education or other studies); b) specialty that follow the student; this specialty may affect the scores, as different score is needed in each of them to access the university; c) access method to the university; whether the students pass the examination required to enter the university or they came from another career of from vocational training.

The results are displayed on Table 5. We found no difference by method of access to the studies of education. For last time of study the was a significant result in the behavioural towards teaching of probability component (BT) and a highly significant result in perceived competence in probability; in both cases the results favoured to those who had studied probability more recently than their colleagues. As regard the speciality the several differences favour those who needed a higher score to enter the school of Education.

\section{DISCUSSION AND RESEARCH PERSPECTIVES}

In this new sample, the results again suggest a positive attitude towards probability and its teaching that reproduce those obtained in the pilot samples in Estrada et al. (2018). These attitudes are better than attitudes towards statistics reported in previous studies so that the topic seems to be more valuable for prospective 
teachers in our sample who are more willing to teach probability than statistics. Given the coincidence of the results with the pilot studies and the high reliability of the instrument, these results are likely to be replicated with other prospective Spanish teachers.

Since teachers tend to transmit their attitudes to their students these results suggest the need to prepare the teachers who feel not too confident in their own capacities for learning and for teaching probability. It is well known the strong influences of the affective domain in the learning of mathematics, because the possible influence of this domain on the cognitive processes related to mathematical thinking, such as, for example, creativity, visualization, intuition or argumentation (Gómez-Chacón, 2016). There is an additional mutual relationship between the affective dimension and learning, since the students' experience in learning mathematics affects their emotions and beliefs that, in turn, have a strong influence on their ability to learn (Gil, Blanco, \& Guerrero, 2006). Our suggestion to improve attitudes for these components is to have teachers explore different methods for teaching probability and gain confidence in their ability to learn and to teach probability.

In agreement with Goldin et al. (2016), more research aimed at describing the different profiles of attitudes in teachers is required, as well as research investigating their origin; in particular, it is important to describe the role of didactical, social, and cultural factors in the development of recurrent profiles of attitudes, which can be achieved by comparing prospective teachers' attitudes in different countries, cultures, and school systems.

A second line of research is taking into account the role of non-cognitive factors such as attitudes and motivations in the education of teachers to teach probability, given the relevance of attitudes in teaching and learning (Gal \& Ginsburg, 1994). A first step is making teachers conscious of the relevance of their attitudes and preparing them to use scales such as the one developed in our research to assess their own attitudes and those of their students.

\section{ACKNOWLEDGEMENT}

Research supported by the project: EDU2016-74848-P (AEI, FEDER).

\section{Disclosure statement}

No potential conflict of interest was reported by the authors.

\section{Notes on contributors}

Assumpta Estrada - University of Lleida, Spain.

Carmen Batanero - University of Granada, Spain.

\section{REFERENCES}

Ajzen, I. (1989). Attitude structure and behavior. In A. Pratkanis, S. Breckler, \& A. Greenwald (Eds.), Attitude structure and function (pp. 241-274). Hillsdale, NJ: Erlbaum.

Attard, C., Ingram, N., Forgasz, H., Leder, G., \& Grootenboer, P. (2016). Mathematics education and the affective domain. In K. Makar, S. Dole, J. Visnovska, M. Goos, A. Bennison, \& K. Fry (Eds), Research in Mathematics Education in Australasia 2012-2015 (pp. 73-96). Springer, Singapore. https://doi.org/10.1007/978-981-10-1419-2_5

Australian Curriculum, Assessment and Reporting Authority [ACARA]. (2010). Australian Curriculum: Mathematics. Sidney, NSW: Author. Retrieved from http://www.australiancurriculum.edu.au/ Mathematics/Rationale

Auzmendi, E. (1992). Las actitudes hacia la matemática estadística en las enseñanzas medias y universitarias (Attitudes towards teaching mathematics in high school and university). Bilbao: Mensajero.

Batanero, C., Arteaga, P., Serrano, L., \& Ruiz, B. (2014). Prospective primary school teachers' perception of randomness. In E. Chernoff \& B. Sriraman (Eds.), Probabilistic thinking: Presenting plural perspectives (pp. 345-366). New York: Springer. https://doi.org/10.1007/978-94-007-7155-0_19 
Batanero, C., Chernoff, E., Engel, J. Lee, H, \& Sánchez, E. (2016). Research on teaching and learning probability. ICME-13. Topical Survey series. New York: Springer. https://doi.org/10.1007/978-3-31931625-3

Carmona, J. (2004). Una revisión de las evidencias de fiabilidad y validez de los cuestionarios de actitudes y ansiedad hacia la estadística (Revising the reliability and validity evidence of attitudes and anxiety towards statistics questionnaires). Statistics Education Research Journal, 1(1), 5-28. Retrieved on 12 February 2019 from www.stat.auckland.ac.nz/ iase/serj/

Chick, H. L., \& Pierce, R. U. (2008). Teaching statistics at the primary school level: Beliefs, affordances, and pedagogical content knowledge. In C. Batanero, G. Burrill, C. Reading, \& A. Rossman (2008). (Eds.). Proceedings of the Joint ICMI/IASE Study: Teaching statistics in school mathematics - Challenges for teaching and teacher education. Proceedings of the ICMI Study 18 and 2008 IASE Round Table Conference. Monterrey, Mexico: International Commission on Mathematical Instruction e International Association for Statistical Education.

Common Core State Standards Initiative (CCSSI). (2010). Common Core State Standards for Mathematics. Washington, DC: National Governors Association for Best Practices and the Council of Chief State School Officers. Retrieved on 30 June 2019 from www.corestandards.org/Math/

Di Martino, P., \& Zan, R. (2015). The construct of attitude in mathematics education. In B. Pepin \& B. Roesken-Winter (Eds.), From beliefs to dynamic affect systems in mathematics education: Exploring a mosaic of relationships and interactions (pp. 51-72). New York: Springer. https://doi.org/10.1007/9783-319-06808-4_3

Estrada, A. (2002). Análisis de las actitudes y conocimientos estadísticos elementales en la formación del profesorado (Analysis of attitudes and statistical knowledge in teacher' education). Ph.D. dissertation. Universidad Autónoma de Barcelona, Spain. Retrieved on 18 April 2019 from www.tesisenxarxa.net/TDX-0502103-191818/

Estrada, A., \& Batanero, C. (2008). Explaining teachers' attitudes towards statistics. In C. Batanero, G. Burrill, C. Reading, \& A. Rossman, (Eds.). Proceedings of the Joint ICMI/IASE Study: Teaching statistics in school mathematics - Challenges for teaching and teacher education. Proceedings of the ICMI Study 18 and 2008 IASE Round Table Conference. Monterrey, México: International Commission on Mathematical Instruction e International Association for Statistical Education.

Estrada, A., Batanero, C., \& Díaz, C. (2018). Exploring teachers' attitudes towards probability and its teaching. In C. Batanero \& E. Chernoff (Eds.), Teaching and learning stochastics (pp. 313-332). Springer, Cham. https://doi.org/10.1007/978-3-319-72871-1_18

Estrada, A., Batanero, C., \& Lancaster, S. (2011). Teachers' attitudes towards statistics. In C. Batanero, G. Burrill, \& C. Reading (Eds.), Teaching statistics in school mathematics. Challenges for teaching and teacher education (pp. 173-174). Springer.Estrada, A., Bazán, J. L., \& Aparicio, A. (2010). A crosscultural psychometric evaluation of the attitude statistic scale Estrada's in teachers. Em C. Reading (Ed.), Data and context in statistics education: Towards an evidence-based society. Proceedings of Eigth International Conference on Teaching of Statistics (ICOTS 8). Ljubljana. Slovenia, Voorburg, The Netherlands: International Statistical Institute. https://doi.org/10.1007/978-94-007-1131-0_18

Estrada, A., Batanero, C., Fortuny, J. M., \& Diaz, C. (2005). A structural study of future teachers' attitudes towards statistics. In M. Bosch (Ed.), Proceedings of the Fourth Congress of the European Society for Research in Mathematics Education (pp. 508-517). Barcelona: IQS Fundemi.

Gal, I. (2005). Towards" probability literacy" for all citizens: Building blocks and instructional dilemmas. In G. A. Jones (Ed.), Exploring probability in school (pp. 39-63). Boston, MA: Springer. https://doi.org/10.1007/0-387-24530-8_3

Gal, I., \& Ginsburg, L. (1994). The role of beliefs and attitudes in learning statistics: Towards an assessment framework. Journal of Statistics Education, 2(2). Retrieved on 24 May 2019 from www.amstat.org/publications/jse/v2n2/gal.html

Gal, I., Ginsburg, L., \& Schau, C. (1997). Monitoring attitudes and beliefs in statistics education. In I. Gal \& J. B. Garfield (Eds.), The assessment challenge in statistics education (pp. 37-51). Voorburg, Netherlands: IOS Press.

Gil, N., Blanco, L., \& Guerrero E. (2006). The affective domain in mathematics learning. International Electronic Journal of Mathematics Education, 1(1), 16-32. 
Goldin, G., Hannula, M., Heyd, E., Jansen, A., Kaasila, R., Lutovac, S., Di Martino, P., Morselli, F., Middeleton, J., Pantziara, M., \& Zhang, Q. (2016). Attitudes, beliefs, motivation and identity in mathematics education. ICME-13 Topical Surveys. New York: Springer. https://doi.org/10.1007/978-3-319-32811-9

Gómez-Chacón, I. (2000) Affective influences in the knowledge of mathematics, Educational Studies in Mathematics, 43(2), 149-168. https://doi.org/10.1023/A:1017518812079

Gómez-Chacón, I. (2016). Métodos empíricos para la determinación de estructuras de cognición y afecto en matemáticas. En A. Berciano et al. (Eds.). Investigación en Educación Matemática XX (pp. 93-114). Malaga: Sociedad Española de Investigación en Educación Matemática.

Groth, R., \& Meletiou-Mavrotheris, M. (2018). Research on statistics teachers' cognitive and affective characteristics. In D. Ben-Zvim (Ed,), International handbook of research in statistics education (pp. 327-355). Springer, Cham. https://doi.org/10.1007/978-3-319-66195-7_10

Kislenko, K. (2009). Mathematics is a bit difficult but you need it a lot: Estonian pupils' beliefs about Mathematics. In J. Maab \& W. Schlöglmann (Eds.), Beliefs and attitudes in mathematics education: New research results (pp. 143-163). Rotterdam: Sense Publishers. https://doi.org/10.1163/978908790723 $5 \_012$

Kvatinsky, T., \& Even, R. (2002). Framework for teacher knowledge and understanding of probability. In B. Phillips (Ed.), Proceedings of the Sixth International Conference on Teaching Statistics. Voorburg, The Netherlands: International Statistical Institute. Retrieved on 2 May 2019 from www.icots6.haifa.ac.il/PAPERS/6A4_KVAT.PDF

Lancaster, S. (2008). A study of preservice teachers' attitudes toward their role as students of statistics and implications for future professional development in statistics. C. Batanero, G. Burrill, C. Reading, \& A. Rossman.

Leavy, A. M., Hannigan, A., \& Fitzmaurice, O. (2013). If you're doubting yourself, what's the fun in that? An exploration of why prospective secondary mathematics teachers perceive statistics as difficult. Journal of Statistics Education, 21(3), n3. Retrieved from www.amstat.org/publications/jse/v21n3/leavy.pdf

Liu, Y., \& Thompson, P. (2007). Teachers' understandings of probability. Cognition and Instruction, 25(2-3), 113-160. https://doi.org/10.1080/07370000701301117

Martínez-Sierra, G., \& García González, M. D. S. (2014). High school students' emotional experiences in mathematics classes. Research in Mathematics Education, 16(3), 234-250. https://doi.org/10.1080/14794802.2014.895676

Martins, J. A., Nascimento, M. M., \& Estrada, A. (2012). Looking back over their shoulders: A qualitative analysis of Portuguese teachers' attitudes towards statistics. Statistics Education Research Journal, 11(2), 26-44. Retrieved on 27 March 2016 from www.stat.auckland.ac.nz/ iase/serj/SERJ11(2)_Martins. pdf

Martins, J., Nascimento, M., \& Estrada, A. (2011). Attitudes of teachers towards statistics: a preliminary study with Portuguese teachers. Proceedings of CERME 7. Rzeszow, Poland: ERME. Retrived on 4 May 2019 from www.cerme7.univ.rzeszow.pl/WG/5/CERME_Martins-Nascimento-Estrada.pdf

McDonald, R. P. (2013). Test theory: A unified treatment. Sussex, UK: Psychology Press. https://doi.org/10.4324/9781410601087

McLeod, D. (1992). Research on affect in mathematics education: A reconceptualization. In D.A. Grouws (Ed.), Handbook of research on mathematics teaching and learning (pp. 575-596). New York, NY: Macmillan.

Ministerio de Educación, Cultura y Deporte. (2014). Real Decreto 126/2014, de 28 de febrero, por el que se establece el currículo básico de la Educación Primaria (Royal Decree establishing the minimum content for primary education). Madrid: Author.

Ministry of Education. (2007). The New Zealand curriculum. Wellington, New Zealand: Learning Media.

Nasser, F. M. (2004). Structural model of the effects of cognitive and affective factors on the achievement of arabic-speaking pre-service teachers in introductory statistics Journal of Statistics Education, 12(1). https://doi.org/10.1080/10691898.2004.11910717

National Council of Teachers of Mathematics. (2000). Principles and standards for school mathematics. Reston, VA: Author.

Nolan, M. M., Beran, T., \& Hecker, K. G. (2012). Surveys assessing students' attitudes toward statistics: A systematic review of validity and reliability. Statistics Education Research Journal, 11(2), 103-123. Retrieved from https://www.stat.auckland.ac.nz/ iase/serj/SERJ11(2)_Nolan.pdf 
Nunnally, J. C. (1978). Psychometric theory (2nd ed.). New York: McGraw-Hill.

OECD. (2013). PISA 2012 Assessment and analytical framework: Mathematics, reading, science, problem solving and financial literacy. Paris: OECD Publishing. https://doi.org/10.1787/9789264190511-en

Onwuegbuzie, A. J. (1998). Teachers' attitudes toward statistics. Psychological Reports, 83, 1008-1010. https://doi.org/10.2466/pr0.1998.83.3.1008

Philipp, R. A. (2007). Mathematics teachers' beliefs and affects. In F. Lester (Ed.), Second handbook of research on mathematics teaching and learning (pp. 257-315). Charlotte, NC: Information Age Publishing \& National Council of Teachers of Mathematics.

Ramirez, C., Schau, C., \& Emmioğlu, E. S. (2012). The importance of attitudes in statistics education. Statistics Education Research Journal, 11(2), 57-71.

Roberts, D. M., \& Bilderback, E. W. (1980). Reliability and validity of a statistics attitude survey. Educational and Psychological Measurement, 40(1), 235-238. https://doi.org/10.1177/001316448004000138

Schau, C. (2003, August). Students' attitudes: The other important outcome in statistics education. Paper presented at the Joint Statistical Meeting of the American Statistical Association, San Francisco, CA: American Statistical Association.

Schau, C., Stevens, J., Dauphine, T., \& Del Vecchio, A. (1995). The development and validation of the survey of attitudes towards statistics. Educational and Psychological Measurement, 55(5), 868-875. https://doi.org/10.1177/0013164495055005022

Stohl, H. (2005). Probability in teacher education and development. In G. Jones (Ed.), Exploring probability in schools: Challenges for teaching and learning (pp. 345-366). New York: Springer. https://doi.org/10.1007/0-387-24530-8_15

Tan, C. K., Harji, M. B., \& Lau, S. H. (2011). Fostering positive attitude in probability learning using graphing calculator. Computers \& Education, 57(3), 2011-2024. https://doi.org/10.1016/j.compedu.2011.05.005

Tishkovskaya, S., \& Lancaster, G. (2012). Statistical education in the 21st century: a Review of challenges, teaching innovations and strategies for reform. Journal of Statistics Education, 20(2), 1-24. Retrieved on 9 May 2019 from www.amstat.org/publications/jse/v20n2/tishkovskaya.pdf

Veloo, A., \& Chairhany, S. (2013). Fostering students' attitudes and achievement in probability using teamsgames-tournaments. Procedia - Social and Behavioral Sciences. 93, 59-64. https://doi.org/10.1016/j.sbspro.2013.09.152

Wise, S. L. (1985). The development and validation of a scale measuring attitudes toward statistics. Educational \& Psychological Measurement, 45, 401-405. https://doi.org/10.1177/001316448504500226

Wyer, R. S., \& Albarracín, D. (2014). Belief formation, organisation and change: Cognitive and motivational influences. In D. Albarracìn, T. Johnson, \& M. P. Zanna (Eds.). The handbook of attitudes (pp. 273-322). New York: Psychology Press. 


\section{APPENDIX}

\section{Scale APT: Attitudes towards Probability and its Teaching}

Note: Each item below was followed by a 5-point scale ranging from 1 (strongly disagree) to 5 (strongly agree). Scores in items with negative wordings were rescaled before computing the mean.).

\begin{tabular}{|c|c|c|}
\hline Item & Mean & Std. Dev. \\
\hline I enjoy the lessons in which probability is explained. & 3.15 & 0.82 \\
\hline I use probability information when making decisions. & 3.23 & 0.94 \\
\hline It will be hard for me to teach probability. & 3.32 & 0.99 \\
\hline Probability helps you understand today's world. & 3.61 & 0.89 \\
\hline I like probability; it is a subject that always interested me. & 3.00 & 0.98 \\
\hline Probability is easy. & 2.90 & 0.93 \\
\hline I never used probability outside mathematics. & 3.70 & 1.09 \\
\hline I have mastered the main contents of probability. & 2.75 & 0.93 \\
\hline I am sure I will enjoy teaching probability in school. & 3.36 & 0.92 \\
\hline I think I can notice and correct students' errors and difficulties with probability. & 3.34 & 0.85 \\
\hline I will only teach probability if there is time available after teaching the other topics. & 4.10 & 0.92 \\
\hline Probability is only useful for games of chance. & 4.37 & 0.79 \\
\hline Probability is not as valuable as other areas of mathematics. & 4.13 & 0.89 \\
\hline It will be easy for me to design assessment tasks related to probability. & 2.76 & 0.75 \\
\hline I use probability in everyday life. & 3.38 & 0.95 \\
\hline I feel scared when faced with probability information. & 3.51 & 1.00 \\
\hline Probability is understandable only to "science people." & 4.27 & 0.91 \\
\hline I avoid reading information that contains probability terms (e.g. in drugs prospects). & 3.97 & 1.00 \\
\hline Probability knowledge helps students to reason critically. & 3.76 & 0.80 \\
\hline Probability should be taught since the first teaching levels. & 3.56 & 0.93 \\
\hline I feel worried about being able to reply to my students' questions about probability. & 3.08 & 0.99 \\
\hline I do not feel well enough prepared to solve any basic probability problem. & 3.43 & 1.03 \\
\hline I would not be able to prepare suitable didactic resources for the probability lesson. & 3.70 & 0.93 \\
\hline I will use probability when needed in other topics I teach. & 3.56 & 0.83 \\
\hline If I could skip a topic, I would skip probability. & 4.42 & 0.86 \\
\hline I am not interested in teaching probability, even if it appears in the curriculum. & 4.18 & 0.89 \\
\hline I do not enjoy solving probability problems. & 3.79 & 1.05 \\
\hline As a teacher, I would feel comfortable when teaching probability. & 3.49 & 0.91 \\
\hline
\end{tabular}

